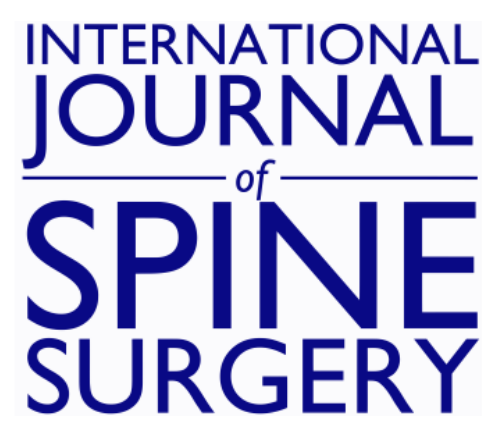

\title{
Synthetic Bone Graft Materials in Spine Fusion: Current Evidence and Future Trends
}

\author{
Mark A. Plantz, Erik B. Gerlach and Wellington K. Hsu
}

Int J Spine Surg 2021, 15 (s1) 104-112

doi: https://doi.org/10.14444/8058

http://ijssurgery.com/content/15/s1/104

This information is current as of April 26, 2023.

Email Alerts Receive free email-alerts when new articles cite this article. Sign up at: http://ijssurgery.com/alerts 


\title{
Synthetic Bone Graft Materials in Spine Fusion: Current Evidence and Future Trends
}

\author{
MARK A. PLANTZ, BS, ERIK B. GERLACH, MD, WELLINGTON K. HSU, MD \\ Department of Orthopaedic Surgery, Northwestern University Feinberg School of Medicine, Chicago, Illinois
}

\begin{abstract}
Historically, iliac crest bone autograft has been considered the gold standard bone graft substitute for spinal fusion. However, the significant morbidity associated with harvesting procedures has influenced decision-making and practice patterns. To minimize these side effects, many clinicians have pursued the use of bone graft extenders to minimize the amount of autograft required for fusion in certain applications. Synthetic materials, including a variety of ceramic compounds, are a class that has been studied extensively as bone graft extenders. These have been used in combination with a wide array of other biomaterials and investigated in a variety of different spine fusion procedures. This review will summarize the current evidence of different synthetic materials in various spinal fusion procedures and discuss the future of novel synthetics.
\end{abstract}

Special Issue

Keywords: synthetics, ceramics, calcium phosphate, hydroxyapatite, bioactive glass, synthetic polymers, 3D printing, composite scaffold

\section{INTRODUCTION}

A number of studies have demonstrated excellent fusion rates and clinical outcomes with the use of iliac crest bone autograft (ICBG) in both lumbar and cervical fusion procedures. ${ }^{1-3}$ However, the burden of donor-site morbidity from ICBG harvesting is both a significant and common occurrence, which has significantly limited its use clinically. ${ }^{4,5}$ There has been extensive research to investigate materials that can either replace or reduce the amount of autograft required to achieve adequate bone healing after spine fusion. ${ }^{6,7}$ Synthetic materials have been studied extensively in a variety of applications to reduce the amount of autograft bone. With current trends in materials science and engineering, it has been postulated that these biomaterials will eventually outperform allograft materials in both efficacy and cost. ${ }^{8}$

There is a wide array of synthetic materials available on the market, with significant variability in biomechanical properties, biodegradability, microscale architecture, and surgical handling properties. ${ }^{9}$ The main categories include ceramics, bioactive glass, and polymer-based compounds. ${ }^{9}$ These materials have been used alone and/or combined with other synthetics and orthobiologics to form composites with unique properties. There are 4 important properties used to classify the bone regenerative capacity of different bone graftsosteoinductivity, osteoconductivity, osteogenesis, and osteointegration. ${ }^{7}$ Osteogenesis is simply the process of bone growth. Osteoinductivity is an active process, whereby osteogenesis, or bone growth, is induced by upregulation of osteogenic signaling pathways and the recruitment and differentiation of stem cells. Osteoconductivity is the ability to support bone growth along the surface or internal structure of a material-by definition a passive process. Osteointegration describes the process by which bony ingrowth provides a secure connection between a material's surface and bone. Synthetics, such as ceramic-based materials, are generally considered to be osteoconductive, but generally lack significant osteoinductive potential. ${ }^{10}$ Hence, although these compounds provide an adequate matrix for bone growth, there is no inherent stimulation of significant bone regeneration. For example, when ceramics are combined with the osteoinductivity from autograft, the properties of both materials are harnessed to provide osteogenic potential and subsequent bone healing. ${ }^{10}$

In addition to osteogenic properties, it is important to consider the host inflammatory response of 
these different synthetic materials. Generally, ceramics, bioactive glass compounds, and synthetic polymers have excellent biocompatibility when used in clinical applications. ${ }^{11-13}$ Furthermore, the biodegradability, which can vary widely, is an important consideration when choosing a synthetic for a particular application. ${ }^{11}$ Careful consideration of the interactions between the graft and host is essential for ensuring safety and circumventing adverse events.

\section{CERAMICS}

\section{Overview}

Generally, the advantages of ceramics are their excellent biocompatibility, biodegradability, and osteoinductive platform. ${ }^{11}$ Overall, the disadvantages of these materials are their minimal mechanical strength, lack of robust osteoinductivity, and their brittleness. ${ }^{11}$ The most commonly used ceramics for bone graft materials are calcium sulfates, calcium phosphates, and hydroxyapatites (HAs). ${ }^{11}$

Calcium sulfate provides an osteoconductive matrix for ingrowth of osteogenic cells, ${ }^{11}$ is biodegradable, and is completely reabsorbed within roughly 5-7 weeks after implantation via dissolution. ${ }^{11}$ This material has been found to degrade faster than the rate of bone deposition and is significantly limited in this respect. Importantly, calcium sulfate requires a dry environment and will soften if exposed to moisture, resulting in reduced strength and increased fragmentation. ${ }^{11}$ Consequently, calcium sulfate has significantly limited mechanical strength, and is not often used in spine fusion ${ }^{14}$ but rather in smaller defect applications. ${ }^{11}$ Calcium sulfate has also been known to cause serous drainage from the surgical site as the graft absorbs, which is another noteale limitation of the material. ${ }^{15}$

Calcium phosphates provide osteoconductivity and osteointegration when used in vivo. ${ }^{11} \mathrm{Com}-$ monly used calcium phosphates include $\beta$-tricalcium phosphate $(\beta-\mathrm{TCP})$, calcium phosphate cement, and HA. These ceramics are strong under compression but are generally limited by their weakness under tension and shear forces. ${ }^{11}$ These materials, when used individually, are also limited by their brittleness. ${ }^{11} \beta$-TCP is a porous calcium phosphate formulation that has a compressive and tensile strength that is comparable with cancellous bone. ${ }^{11}$ Unlike calcium sulfate, $\beta$-TCP has a longer period of degradation-undergoing complete dissolution after 6 to 18 months. ${ }^{11}$ Previous studies have demonstrated that as the material degrades, novel bone production and integration is incomplete, resulting in reduced mechanical stability. ${ }^{11,16}$ Of note, calcium phosphate is also available in cement formulations, that have been demonstrated to have an even longer degradation phase, on the order of 24 months. ${ }^{17}$ Calcium phosphate cement can be mixed, molded, and set during surgery. Given the poor osteoinductivity of calcium phosphates, the use of the material individually as a bone graft substitute is limited. ${ }^{11,16}$ It is typically combined with other products, such as autograft. ${ }^{18}$

$\mathrm{HA}$ is the main component of bone mineral with a porous structure that provides robust osteoconductivity. ${ }^{11}$ Synthetic HA has been engineered to mimic this mineral phase. ${ }^{11}$ Synthetic HA is engineered to have improved compressive strength and toughness, achieved by heating (eg, sintering). ${ }^{19,20}$ Synthetic HA formulations are generally not bioabsorbable, and remain in vivo indefinitely with an estimated absorption rate of $1 \%$ to $2 \%$ per year. ${ }^{11}$ Historically, synthetic HA has not been as porous as natural HA; however, novel techniques have enabled the production of nanostructured synthetic HA. ${ }^{11}$ HA and TCP are often combined with polymers, such as collagen to form ceramic composites and improve mechanical properties. ${ }^{21,22}$

\section{Clinical Efficacy of Ceramic-Based Bone Graft Materials}

Ceramics have historically been used as bone graft extenders, often in combination with autograft materials. ${ }^{10}$ In a recent systematic review, Nickoli and $\mathrm{Hsu}^{10}$ investigated the efficacy of ceramic-based bone grafts in lumbar spinal fusion. Most commonly, ceramics were combined with autograft materials-local autograft, ICBG, and/or bone marrow aspirate (BMA). It was demonstrated that the overall fusion rate for ceramic-based grafts was $86 \%$, and that the specific type of ceramic used did not significantly influence fusion rate (Table 1). ${ }^{10}$ In general, the highest fusion rates were achieved when ceramics were combined with local autograft relative to all other adjunct materials. ${ }^{10}$ This review assessed 30 studies in total; 3 level I studies, 9 level II studies, 3 level III studies, and 14 level IV studies. Importantly, ceramics were used as bone graft extenders (eg, in combination with another adjunct) in all but 2 of the included studies. The average fusion rate in studies using ceramic with local 
Table 1. Summary of ceramic bone graft data from systematic review (Nickoli and Hsu). ${ }^{10}$

\begin{tabular}{lcccc}
\hline & Total Patients, no. & Fused Patients, no. & Overall Fusion Rate, \% & Fusion Rate Range, \% \\
\hline Ceramic only & 69 & 56 & 81.2 & $77.6-90.0$ \\
Ceramic with local autograft & 453 & 407 & 89.8 & $52.6-100.0$ \\
Ceramic with ICBG & 87 & 77 & 88.5 & $78.9-100.0$ \\
Ceramic with BMA & 215 & 156 & 72.6 & $4.5-95.5$ \\
Ceramic with local autograft + BMA & 242 & 221 & 91.3 & $85.0-95.0$ \\
\hline
\end{tabular}

Abbreviations: BMA, bone marrow aspirate; ICBG, iliac crest bone autograft.

autograft was $89.8 \%$ (range, $52.6 \%-100 \%$ ), and with ceramic and ICBG it was $88.5 \%$ (range: $78.9 \%-100 \%) .{ }^{10}$ The fusion rate for ceramics and BMA combinations was demonstrated to be lower, with an average fusion rate of $72.6 \%$ (range, $4.5 \%{ }^{-}$ $95.5 \%) .{ }^{10}$ When ceramics were combined with both local autograft and BMA, the fusion rate was greater-91.3\% (range, $85 \%-95 \%$ ), relative to ceramics and BMA alone. ${ }^{10}$ Notably, in the 2 studies that assessed ceramic alone as a bone graft substitute, the average fusion rate was $81.5 \%$ (range, $77.6 \%-90 \%$ ). ${ }^{10}$ This systematic review also compared the fusion rates between ceramic-based grafts used in different surgical approaches, namely posterolateral fusion (PLF) and circumferential fusion combining interbody fusion with posterior instrumentation - anterior lumbar interbody fusion ( $\mathrm{n}=4$ studies), posterior lumbar interbody fusion (PLIF) ( $\mathrm{n}=6$ studies), and transforaminal lumbar interbody fusion ( $\mathrm{n}=2$ studies). On average, there were no significant differences in fusion rate between PLF alone versus circumferential fusion. ${ }^{10}$ Figure 1 provides a diagram that illustrates how graft materials are used clinically, demonstrating different fusion options (eg, intertransverse fusion and interbody fusion). Despite the heterogeneity of

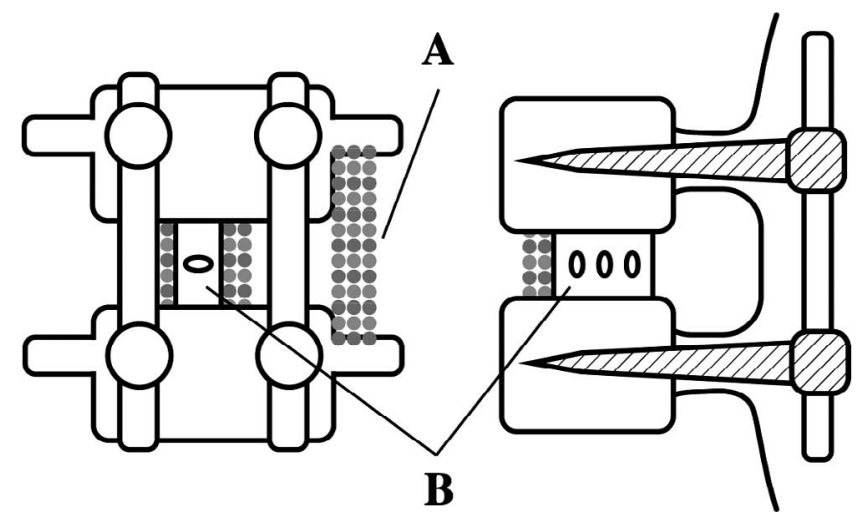

Figure 1. Diagram illustrating a single-level fusion with instrumentation and different options for placement of bone graft material (left: posterior view; right: lateral view). (A) Demonstrates an intertransverse fusion with graft material placed between the transverse processes of adjacent vertebral levels. (B) Demonstrates an interbody fusion with a cage containing graft material placed in between the vertebral bodies of adjacent levels. the included studies, the results are suggestive that ceramic materials are efficacious as a bone graft extender in a variety of applications when combined with an osteoinductive component, such as autograft.

With the increasing popularity of minimally invasive spine surgery (MIS), there has also been interest in the use of different synthetic grafts in this setting. ${ }^{23}$ It has been demonstrated that $\mathrm{HA}$ as a bone graft extender in MIS transforaminal interbody body yields a fusion rate of roughly $88 \%$ with a dose-dependent influence wherein the relative amount of autograft correlated with the fusion rate. ${ }^{23,24}$ Another study demonstrated that the combination therapy of $\beta$-TCP, HA, and bone morphogenetic protein-2 (BMP-2) yielded a $100 \%$ fusion rate in a small cohort of patients undergoing MIS lateral interbody fusion for adult thoracolumbar deformity correction. ${ }^{25}$

Over the last 20 years, several studies have demonstrated the efficacy of various ceramic-based grafts as bone graft extenders (eg, used in combination with other materials) - including Vitoss (Stryker, Kalamazoo, MI), ${ }^{26,27}$ Mastergraft (Medtronic, Minneapolis, MN), ${ }^{28,29}$ nanOss (Surgalign, Deerfield, IL), ${ }^{26,27}$ BoneSave (Stryker), ${ }^{30}$ and ApaPore, among others. Additionally, BoneSave (Stryker) has been evaluated as a standalone bone graft substitute. In a retrospective cohort of 45 patients who underwent posterolateral intertransverse fusion with BoneSave used alone, the graft yielded a fusion rate of $57 \%$ (determined via radiography) with clinical outcomes comparable with more conventional allograft and autograft techniques. ${ }^{31}$

With the potential to manufacture ceramics with bioactivity, there is also increasing interest in using these different materials as standalone bone graft substitutes. More recently, calcium phosphates with submicron topography have been created to improve bioactivity and bone healing properties, including AttraX (NuVasive, San Diego, CA) and MagnetOs (Kuros Biosciences, Schlieren, Switzer- 
land). AttraX, an absorbable biphasic calcium phosphate, has been studied for its efficacy in spine fusion. ${ }^{32}$ In a recent randomized noninferiority trial of 100 patients, Lehr et $\mathrm{al}^{32}$ demonstrated that AttraX Putty used individually yielded similar fusion rates to autograft when used for instrumented PLF - as determined via computed tomography at 1 year postoperatively. AttraX Putty and autograft were implanted on contralateral sides of the fusion bed; therefore, each patient served as their own control. ${ }^{32}$ AttraX Putty yielded a fusion rate of $55 \%$ and autograft yielded a rate of $52 \% .{ }^{32}$ In a different cohort of patients who underwent extreme lateral interbody fusion procedures, Berjano et $\mathrm{al}^{33}$ demonstrated that autograft, calcium triphosphate, and AttraX yielded similar fusion rates $-75 \%, 89 \%$, and $83 \%$, respectively - as determined by computed tomography at 1 year postoperatively. ${ }^{33}$ This product has also been demonstrated to yield fusion rates equivalent to autograft in a sheep PLF model, ${ }^{34}$ determined by manual palpation of the explanted spinal segments at 8,12 , and 26 weeks' postoperatively. It has also been shown to outperform a bioglass-based calcium phosphate product in canine interspinous and intramuscular implantation models, assessed by histological analysis. ${ }^{35}$

Another biphasic calcium phosphate product, MagnetOs (Kuros Biosciences), has been investigated as a bone graft substitute for spinal fusion applications. Van Dijk et $\mathrm{al}^{36}$ demonstrated in a recent preclinical study that both MagnetOs granules and putty formulations yielded $100 \%$ fusion rates, in an ovine instrumented PLF model, as determined via manual palpation of explanted spines. Histological analysis yielded fusion rates of $75 \%, 92 \%$, and $83 \%$ for the autograft, MagnetOs granules, and MagnetOs putty groups, respectively. ${ }^{36}$ In vitro, it has been suggested that the submicron topography of MagnetOs granules may lead to upregulation of M2 macrophages and subsequently improved bone healing relative to conventional calcium phosphate bone grafts. ${ }^{36}$

\section{BIOACTIVE GLASS}

\section{Overview}

Bioactive glasses are metallic oxide materials with the main component silicon dioxide. ${ }^{11,37}$ These materials are hard and nonporous. ${ }^{11,37}$ The biodegradability can be controlled by altering the relative composition of different components-sodium oxide, calcium oxide, and silicon dioxide, respectively. ${ }^{11,37}$ Bioactive glasses, similar to ceramics, provide osteoconductivity and osteointegration when used in vivo. ${ }^{11,37}$ These materials generally have superior mechanical strength when compared with calcium phosphate-based ceramics ${ }^{11,37}$ and provide excellent osteoconductivity despite lacking inherent osteoinductivity. ${ }^{11,37}$ Bioactive glasses also possess osteostimulative properties, allowing for acceleration of bone healing and growth in vivo. ${ }^{38}$

\section{Clinical Efficacy of Bioactive Glass Bone Graft Materials}

Recent systematic reviews have summarized the clinical efficacy of bioactive glasses in spine fusion. ${ }^{39,40}$ In a recent systematic review, Cottrill et $\mathrm{al}^{39}$ summarized the current clinical and preclinical evidence regarding the use of bioactive glasses in spinal fusion, which comprised 12 preclinical $(\mathrm{n}=$ 267 animals) and 12 clinical studies (396 patients) in total. Regarding the evidence level of the 12 clinical studies, no studies were level I, 5 were level II, 1 was level III, and 6 were level IV. Across all 12 clinical studies, when used as a bone graft extender with local autograft, the average fusion rate of bioactive glasses $(89.6 \%, 95 \%$ confidence interval: $76.6 \%-$ $97.7 \%$ ) was similar to autograft alone $(91.6 \%$, $86.0 \%-95.9 \%$ ), and there was no statistically significant difference between the 2 groups. ${ }^{39}$ The surgical procedures in the various studies were as follows: anterior thoracolumbar fusion $(n=2)$, posterior lumbar fusion (eg, PLF, PLIF) $(\mathrm{n}=9)$, and 1 study assessed both cervical and posterior lumbar spinal fusion $(\mathrm{n}=1){ }^{39}$ When used as a standalone bone graft, however, the average fusion rates of bioactive glasses $(33.6 \%)$ were substantially inferior to those of autograft alone $(98.8 \%) .{ }^{39}$ This difference was noted to be statistically significant in quantitative analyses. Of note, 5 different bioactive glasses were studied across the different clinical studies- $533 P 4\left(53 \% \mathrm{SiO}_{2}, 23 \% \mathrm{Na}_{2} \mathrm{O}, 20 \% \mathrm{CaO}\right.$, and $4 \% \mathrm{P}_{2} \mathrm{O}_{5}$ ), $A W-G C$ (apatite- and wollastoniteglass ceramic composite; $34.2 \% \mathrm{SiO}_{2}, 44.9 \% \mathrm{CaO}$, $16.3 \% \mathrm{P}_{2} \mathrm{O}_{5}, 4.6 \% \mathrm{MgO}$, and $\left.0.5 \% \mathrm{CaF}_{2}\right), 45 \mathrm{~S} 5$ $\left(45 \% \mathrm{SiO}_{2}, 24.5 \% \mathrm{Na}_{2} \mathrm{O}, 24.5 \% \mathrm{CaO}\right.$, and $6 \%$ $\left.\mathrm{P}_{2} \mathrm{O}_{5}\right)$, Chitra- $\mathrm{HABg}(80 \% \mathrm{HA}$ and $20 \%$ bioactive glass), and $B G S-7\left(35.82 \% \mathrm{SiO}_{2}, 41.79 \% \mathrm{CaO}\right.$, $13.93 \% \mathrm{P}_{2} \mathrm{O}_{5}, 5.97 \% \mathrm{MgO}, 1.99 \% \mathrm{CaF}_{2}$, and $0.5 \%$ $\left.\mathrm{B}_{2} \mathrm{O}_{3}\right){ }^{39}$ 
Bioactive glasses have been investigated as standalone bone graft substitutes in matched, prospective control trials. Frantzén et $\mathrm{al}^{41}$ published a long-term prospective cohort study of 17 patients (41 fusion levels) undergoing instrumented PLF with S53P4 bioactive glass versus autograft. Each patient served as their own control-with S53P4 and autograft implanted on either side of the fusion site. ${ }^{41}$ As determined by computed tomography, the overall fusion rates were $88 \%$ for the S53P4 sites and $100 \%$ for the autograft sites. ${ }^{41}$ In another study, Rantakokko et $\mathrm{al}^{42}$ compared S53P4 versus autograft alone in patients undergoing instrumented PLF for unstable lumbar burst fractures. Each patient served as their own control-with each graft type implanted on either side of the fusion. ${ }^{42}$ Total fusion rates were $71 \%$ for the S53P4 sites and $100 \%$ for the autograft sites. ${ }^{42}$ Ameri et $\mathrm{al}^{43}$ compared metalderived bioactive glass (NovaBone) with local autograft versus ICBG with local autograft in patients undergoing instrumented posterior fusion for adolescent idiopathic scoliosis-both groups yielded excellent results with comparable average loss of corrections. Fifteen percent of patients in the ICBG group and $10 \%$ of patients in the bioactive group had indeterminate fusions, determined by radiography. ${ }^{43}$ There were no definitive cases of pseudoarthrosis in either group. ${ }^{43}$

Given the heterogeneity in the many variables assessed in these studies - surgical procedure, bone graft material, and patient profile - it is difficult to make specific conclusions regarding the optimal bioactive glass for a particular application. Nonetheless, the aforementioned studies suggest bioactive glasses yield excellent results as bone graft extenders when combined with autograft for spinal fusion. There are limited data regarding the efficacy of bioactive glasses as standalone bone graft substitutes, however. Further investigation of these materials with prospective studies and randomized control trials is warranted to achieve higher quality evidence.

\section{Synthetic Polymers}

Commonly used synthetic polymers in scaffolds for bone grafts include poly(L-lactic) acid, poly(lactic-co-glycolic acid), poly(e-caprolactone), and polymethylmethacrylate (PMMA). ${ }^{13}$ There are a number of techniques for producing these polymer compounds, including electrospinning, solvent casting, and 3D-printing. ${ }^{13}$ Although polymer scaffolds can be engineered to have an architecture that is osteoconductive, they are not inherently osteoinductive. Generally, both synthetic polymer materials have excellent biocompatibility and are often used as the base material for composites - often being combined with ceramics, autograft, and even for local delivery of growth factors. ${ }^{13,44-46}$

\section{Clinical Efficacy of Polymer-Based Bone Graft Materials}

In a recent systematic review, Buser et $\mathrm{al}^{47}$ summarized the efficacy of different synthetic bone grafts relative to autograft or allograft in spine fusion. Among other studies in this review, there were 8 studies that assessed the efficacy of different polymer-based bone grafts in lumbar or cervical fusion. Four studies assessed collagen and HA composite (Healos; DePuy Synthes, Raynham, MA), 3 studies assessed PMMA, and 1 study compared a biocompatible osteoinductive polymer composite.

In the 4 studies investigating $\mathrm{HA}+$ collagen (Healos; DePuy Synthes), there was 1 randomized controlled trial (RCT), 2 prospective cohort studies, and 1 retrospective study. ${ }^{48-51}$ The RCT compared the combination of Healos, BMA, and local autograft versus local autograft and allograft in posterolateral lumbar fusion for patients with degenerative scoliosis, demonstrating no differences in fusion rate, pain scores, function scores, or curve progression at 24 months' postoperatively. ${ }^{48}$ However, the rate of fusion was slower for the Healos group. ${ }^{48}$ The 2 prospective cohort studies compared Healos + BMA versus ICBG alone in posterior lumbar fusion-1 study assessed PLF, PLIF, and combined PLF + PLIF, and the other study assessed combined PLF + PLIF. ${ }^{49,50}$ The first study found that HA + collagen + BMA and ICBG yielded similar radiographic fusion rates when used for posterolateral lumbar fusion $(93.3 \%$ for both grafts), but that Healos + BMA underperformed ICBG $(84.6 \%$ versus $92.3 \%$ fusion rate, respectively) when used for lumbar interbody fusion. ${ }^{49}$ The other study found no difference in fusion rates between the groups. ${ }^{50}$ In the retrospective cohort, $\mathrm{HA}+$ collagen + BMA was found to be inferior to local bone alone, yielding lower fusion rates in posterolateral lumbar fusion. ${ }^{51}$

Of the 3 studies that compared PMMA to autograft, 1 study assessed PLIF and the other 2 assessed anterior cervical discectomy and 
fusion. ${ }^{52-54}$ The first study found no difference in various outcome measures, including functional score measures, between the pedicle screw augmentation with PMMA versus ICBG in PLIF procedures. $^{52}$ The other 2 studies were RCTs comparing PMMA to ICBG, and both studies found that PMMA yielded significantly lower fusion rates than ICBG $(0 \%-30 \%$ versus $86 \%-93 \%$, respectively), although there were no significant differences in various patient outcome measures. ${ }^{53,54}$ One final study compared a biocompatible osteoinductive PMMA-based composite material to ICBG, although none of the patients receiving the PMMAbased composite yielded fusion, compared with a $96 \%$ fusion rate in the ICBG group. ${ }^{55}$

Although there are a wide range of polymerbased composites for use in spine fusion, the most robust evidence exists for HA + collagen composites combined with autologous materials, such as BMA. Notably, combining HA + collagen with BMA successfully eliminated the need for harvesting iliac crest bone graft in some cohorts. This has the potential to greatly reduce donor-site morbidity and other complications associated with ICBG harvesting. 5

\section{FUTURE DIRECTIONS: 3D-PRINTED COMPOSITE MATERIALS}

The use of additive manufacturing technologies in spine surgery has grown significantly within the last decade. ${ }^{56}$ In addition to $3 \mathrm{D}$-printed surgical guides and individualized implants, this technology has also been harnessed to produce composite materials with specific microscale properties that are conducive to osteogenesis. Some groups have designed 3D-printed titanium cages with internal architecture that optimizes mechanical properties, osteoblast activity, and bony ingrowth. ${ }^{57,58}$ These 3D-printed structures may have the potential to obviate the need for additional packing of ceramictype materials. Additive manufacturing provides an efficient means to control the microarchitecture, and subsequently, the biologic activity of a specific material. ${ }^{6,13}$ Techniques using calcium phosphate and HA as the ink component have been used in multiple studies to elicit bone regeneration. ${ }^{59-61}$ There are also a number of techniques for 3Dprinting polymer compounds, including fused deposition, stereolithography, and laser sintering that have enabled researchers to produce synthetic scaffolds to precisely control the architecture and mimic physical cues for bone growth found in native bone. $^{13,62-64}$ These techniques have been used to produce polymer compounds with osteoconductive properties that are conducive to angiogenesis and osteogenesis both in vitro and in vivo. ${ }^{65,66}$

One example is Hyperelastic Bone (Dimension Inx, Chicago, IL) ${ }^{67}$ which has bone regenerative capacity and elasticity, thereby providing optimal surgical handling properties for deployment and use in the operating room. The material is mainly comprised of HA and a polymer binder - capable of being 3D-printed at a rate of up to $275 \mathrm{~cm}^{3} /$ hour. ${ }^{67}$ This material has shown promise in a number of preclinical models, yielding bone growth in vitro, in a mouse subcutaneous implant model, and in a primate calvarial defect model. ${ }^{67}$ Notably, this material was demonstrated to yield a $92 \%$ fusion rate in a rat PLF model, with evidence of osteointegration and bony ingrowth into the scaffold itself. ${ }^{68}$ The degradation and resorption characteristics of Hyperelastic Bone are still being investigated. Pilot studies are underway to fine-tune the degradation rate by adjusting material composition to further optimize the bridging bone formation across adjacent spinal segments. A recent study demonstrated that degradation byproducts of Hyperelastic Bone did not significantly reduce the viability of human mesenchymal stem cells (hMSCs), demonstrating a favorable cell cytotoxicity profile. ${ }^{69}$

Further research has led to the development of a 3D-printed HA and demineralized bone matrix (DBM) composite scaffold-wherein the DBM component provides osteoinductivity - which has demonstrated excellent osteogenic properties both in vitro and in vivo. ${ }^{68} 3 \mathrm{D}$-printing technology has allowed for optimization of material porosity, microarchitecture, and composition to maximize the osteogenic potential of the material. ${ }^{66,68}$ Further preclinical studies are underway to compare this 3D-printed HA-DBM composite to rhBMP-2, a biologic with well-known efficacy in eliciting spine fusion in both humans and animal models. ${ }^{70}$ The preclinical performance of this HA-DBM composite suggests that the material shows promise as a bone graft substitute for spine fusion without the need for autograft or recombinant growth factor (eg, BMP2). As 3D-printing technologies become more robust, mainstream, and cost-effective, 3D-printed synthetics that are deployable in the operating room 
may become a reality for a variety of bone graft applications, including spine fusion.

\section{CONCLUSION}

With advancements in material science and engineering, the ability to finely tune the biologic properties of various synthetic materials has spurred significant growth in the field of bone grafts. Synthetics - including ceramics, glass ceramics, and polymer-based compounds - continue to yield excellent efficacy as bone graft extenders across a variety of spinal fusion procedures, while minimizing the need for autograft. Although many synthetics, such as ceramics, have historically been used in combination with autograft as bone graft extenders, current translational research suggests that perhaps synthetic and biologic composites could yield adequate bone healing without the need for autograft or high-dose growth factors. Furthermore, novel 3D-printing technology has greatly enhanced the ability to control material microarchitecture, which has the potential to greatly enhance the mechanical and bone regenerative properties of interbody cages and bone graft materials. Given the known complications of both autograft harvesting and high-dose growth factors, these materials have the potential to make a real impact on patient care and surgical outcomes.

\section{REFERENCES}

1. Sengupta DK, Truumees E, Patel CK, et al. Outcome of local bone versus autogenous iliac crest bone graft in the instrumented posterolateral fusion of the lumbar spine. Spine. 2006;31(9):985-991.

2. Tuchman A, Brodke DS, Youssef JA, et al. Iliac crest bone graft versus local autograft or allograft for lumbar spinal fusion: a systematic review. Global Spine J. 2016;6(6):592-606.

3. Tuchman A, Brodke DS, Youssef JA, et al. Autograft versus allograft for cervical spinal fusion: a systematic review. Global Spine J. 2017;7(1):59-70.

4. Kalk WW, Raghoebar GM, Jansma J, Boering G. Morbidity from iliac crest bone harvesting. J Oral Maxillofac Surg. 1996;54(12):1424-1429.

5. Arrington ED, Smith WJ, Chambers HG, Bucknell AL, Davino NA. Complications of iliac crest bone graft harvesting. Clin Orthop Relat Res. 1996;329:300-309.

6. Plantz MA, Hsu WK. Recent research advances in biologic bone graft materials for spine surgery. Curr Rev Musculoskelet Med. 2020:1-8.

7. Fillingham Y, Jacobs J. Bone grafts and their substitutes. Bone Joint J. 2016;98(1 suppl A):6-9.

8. Bohner M, Galea L, Doebelin N. Calcium phosphate bone graft substitutes: failures and hopes. $J$ Eur Ceramic Soc. 2012;32(11):2663-2671.
9. Costantino PD, Friedman CD. Synthetic bone graft substitutes. Otolaryngol Clin North Am. 1994;27(5):1037-1074.

10. Nickoli MS, Hsu WK. Ceramic-based bone grafts as a bone grafts extender for lumbar spine arthrodesis: a systematic review. Global Spine J. 2014;4(3):211-216.

11. Moore WR, Graves SE, Bain GI. Synthetic bone graft substitutes. ANZ J Surg. 2001;71(6):354-361.

12. Krishnan V, Lakshmi T. Bioglass: a novel biocompatible innovation. J Adv Pharm Technol Res. 2013;4(2):78.

13. Lyons JG, Plantz MA, Hsu WK, Hsu EL, Minardi S. Nanostructured biomaterials for bone regeneration. Front Bioeng Biotechnol. 2020;8:922.

14. Glazer PA, Spencer UM, Alkalay RN, Schwardt J. In vivo evaluation of calcium sulfate as a bone graft substitute for lumbar spinal fusion. Spine J. 2001;1(6):395-401.

15. Beuerlein MJ, McKee MD. Calcium sulfates: what is the evidence? J Orthop Trauma. 2010;24(suppl 1):S46-S51.

16. Hollinger JO, Brekke J, Gruskin E, Lee D. Role of bone substitutes. Clin Orthop Relat Res. 1996;324:55-65.

17. Russell TA, Leighton RK, Group A-BTPFS. Comparison of autogenous bone graft and endothermic calcium phosphate cement for defect augmentation in tibial plateau fractures: a multicenter, prospective, randomized study. J Bone Joint Surg Am. 2008;90(10):2057-2061.

18. Burger EL, Patel V. Calcium phosphates as bone graft extenders. Orthopedics. 2007;30(11):939-942.

19. Ruys A, Wei M, Sorrell C, Dickson M, Brandwood A, Milthorpe B. Sintering effects on the strength of hydroxyapatite. Biomaterials. 1995;16(5):409-415.

20. Aminzare M, Eskandari A, Baroonian M, et al. Hydroxyapatite nanocomposites: synthesis, sintering and mechanical properties. Ceramics Int. 2013;39(3):2197-2206.

21. Carter JD, Swearingen AB, Chaput CD, Rahm MD. Clinical and radiographic assessment of transforaminal lumbar interbody fusion using HEALOS collagen-hydroxyapatite sponge with autologous bone marrow aspirate. Spine $J$. 2009;9(6):434-438.

22. Gleeson J, Plunkett N, O'Brien F. Addition of hydroxyapatite improves stiffness, interconnectivity and osteogenic potential of a highly porous collagen-based scaffold for bone tissue regeneration. Eur Cell Mater. 2010;20(218):30.

23. Greene AC, Hsu WK. Orthobiologics in minimally invasive lumbar fusion. J Spine Surg. 2019;5(suppl 1):S11.

24. Yoo J-S, Min S-H, Yoon S-H. Fusion rate according to mixture ratio and volumes of bone graft in minimally invasive transforaminal lumbar interbody fusion: minimum 2-year follow-up. Eur J Orthop Surg Traumatol. 2015;25(1):183-189.

25. Dakwar E, Cardona RF, Smith DA, Uribe JS. Early outcomes and safety of the minimally invasive, lateral retroperitoneal transpsoas approach for adult degenerative scoliosis. Neurosurg Focus. 2010;28(3):E8.

26. Epstein NE. Preliminary documentation of the comparable efficacy of vitoss versus NanOss bioactive as bone graft expanders for posterior cervical fusion. Surg Neurol Int. 2015;6(suppl 4):S164.

27. Epstein NE. Preliminary study showing safety/efficacy of nanoss bioactive versus vitoss as bone graft expanders for lumbar noninstrumented fusions. Surg Neurol Int. 2015;6(suppl 10):S318.

28. Smucker JD, Petersen EB, Fredericks DC. Assessment of MASTERGRAFT PUTTY as a graft extender in a rabbit posterolateral fusion model. Spine. 2012;37(12):1017-1021. 
29. Smucker JD, Petersen EB, Nepola JV, Fredericks DC. Assessment of MASTERGRAFT ${ }^{\circledR}$ STRIP with bone marrow aspirate as a graft extender in a rabbit posterolateral fusion model. Iowa Orthop J. 2012;32:61.

30. Blom A, Cunningham J, Hughes $G$, et al. The compatibility of ceramic bone graft substitutes as allograft extenders for use in impaction grafting of the femur. $J$ Bone Joint Surg Br. 2005;87(3):421-425.

31. Kapur RA, Amirfeyz R, Wylde V, Blom A, Nelson I, Hutchinson J. Clinical outcomes and fusion success associated with the use of BoneSave in spinal surgery. Arch Orthop Trauma Surg. 2010;130(5):641-647.

32. Lehr AM, Oner FC, Delawi D, et al. Efficacy of a standalone microporous ceramic versus autograft in instrumented posterolateral spinal fusion: a multicenter, randomized, intrapatient controlled, noninferiority trial. Spine. 2020;45(14):944.

33. Berjano P, Langella F, Damilano M, et al. Fusion rate following extreme lateral lumbar interbody fusion. Eur Spine J. 2015;24(3):369-371.

34. Cunningham BW, Vizesi F, Hu N, de Groot FB, Erbe E, DeBruijn J. Biomechanical evaluation of fusion in the sheep posterolateral fusion model with a novel TCP bone graft substitute. Spine J. 2012;12(9):S121.

35. Barbieri D, Yuan H, Ismailoğlu AS, de Bruijn JD. Comparison of two moldable calcium phosphate-based bone graft materials in a noninstrumented canine interspinous implantation model. Tissue Eng Part A. 2017;23(23-24):13101320.

36. van Dijk LA, Duan R, Luo X, et al. Biphasic calcium phosphate with submicron surface topography in an Ovine model of instrumented posterolateral spinal fusion. JOR Spine. 2018;1(4):e1039.

37. Fernandez de Grado G, Keller L, Idoux-Gillet Y, et al. Bone substitutes: a review of their characteristics, clinical use, and perspectives for large bone defects management. $J$ Tissue Eng. 2018;9:2041731418776819.

38. Al-Harbi N, Mohammed H, Al-Hadeethi Y, et al. Silicabased bioactive glasses and their applications in hard tissue regeneration: a review. Pharmaceuticals. 2021;14(2):75.

39. Cottrill E, Pennington Z, Lankipalle N, et al. The effect of bioactive glasses on spinal fusion: a cross-disciplinary systematic review and meta-analysis of the preclinical and clinical data. J Clin Neurosci. 2020;78:34-46.

40. Salamanna F, Tschon M, Borsari V, Pagani S, Martini L, Fini M. Spinal fusion procedures in the adult and young population: a systematic review on allogenic bone and synthetic grafts when compared to autologous bone. J Mater Sci Mater Med. 2020;31(6):1-20.

41. Frantzén J, Rantakokko J, Aro HT, et al. Instrumented spondylodesis in degenerative spondylolisthesis with bioactive glass and autologous bone: a prospective 11-year follow-up. $J$ Spinal Disord Tech. 2011;24(7):455-461.

42. Rantakokko J, Frantzén JP, Heinänen J, et al. Posterolateral spondylodesis using bioactive glass S53P4 and autogenous bone in instrumented unstable lumbar spine burst fractures. A prospective 10-year follow-up study. Scand J Surg. 2012;101(1):66-71.

43. Ameri E, Behtash H, Mobini B, Omidi-Kashani F, Nojomi M. Bioactive glass versus autogenous iliac crest bone graft in adolescent idiopathic scoliosis surgery. Acta Medica Iranica. 2009:41-45.
44. Wang F. Combinations of calcium phosphates, bone growth factors, and pore-forming additives as osteoconductive and osteoinductive composite bone grafts. In: Google Patents; 2004.

45. Lu S, McGough MA, Shiels SM, et al. Settable polymer/ ceramic composite bone grafts stabilize weight-bearing tibial plateau slot defects and integrate with host bone in an ovine model. Biomaterials. 2018;179:29-45.

46. Haugen HJ, Lyngstadaas SP, Rossi F, Perale G. Bone grafts: which is the ideal biomaterial? J Clin Periodontol. 2019;46:92-102.

47. Buser Z, Brodke DS, Youssef JA, et al. Synthetic bone graft versus autograft or allograft for spinal fusion: a systematic review. J Neurosurg Spine. 2016;25(4):509-516.

48. Ploumis A, Albert TJ, Brown Z, Mehbod AA, Transfeldt EE. Healos graft carrier with bone marrow aspirate instead of allograft as adjunct to local autograft for posterolateral fusion in degenerative lumbar scoliosis: a minimum 2-year follow-up study. J Neurosurg Spine. 2010;13(2):211-215.

49. Neen D, Noyes D, Shaw M, Gwilym S, Fairlie N, Birch N. Healos and bone marrow aspirate used for lumbar spine fusion: a case controlled study comparing healos with autograft. Spine. 2006;31(18):E636-E640.

50. Kitchel SH. A preliminary comparative study of radiographic results using mineralized collagen and bone marrow aspirate versus autologous bone in the same patients undergoing posterior lumbar interbody fusion with instrumented posterolateral lumbar fusion. Spine J. 2006;6(4):405-411.

51. Kunakornsawat S, Kirinpanu A, Piyaskulkaew C, Sathira-Angkura V. A comparative study of radiographic results using HEALOS collagen-hydroxyapatite sponge with bone marrow aspiration versus local bone graft in the same patients undergoing posterolateral lumbar fusion. J Med Assoc Thai. 2013;96(8):929-935.

52. Xie Y, Fu Q, Chen Z-q, et al. Comparison between two pedicle screw augmentation instrumentations in adult degenerative scoliosis with osteoporosis. BMC Musculoskelet Disord. 2011;12(1):1-7.

53. Bärlocher CB, Barth A, Krauss JK, Binggeli R, Seiler RW. Comparative evaluation of microdiscectomy only, autograft fusion, polymethylmethacrylate interposition, and threaded titanium cage fusion for treatment of single-level cervical disc disease: a prospective randomized study in 125 patients. Neurosurg Focus. 2002;12(1):1-7.

54. Orief T, Ramadan I, Seddik Z, Kamal M, Rahmany M, Takayasu M. Comparative evaluation of bone-filled Polymethylmethacrylate implant, autograft fusion, and Polyetheretherketone cervical cage fusion for the treatment of single-level cervical disc disease. Asian J Neurosurg. 2010;5(2):46.

55. Abou Madawi A, Powell M, Crockard HA. Biocompatible osteoconductive polymer versus iliac graft: a prospective comparative study for the evaluation of fusion pattern after anterior cervical discectomy. Spine. 1996;21(18):2123-2129.

56. Wilcox B, Mobbs RJ, Wu A-M, Phan K. Systematic review of $3 \mathrm{D}$ printing in spinal surgery: the current state of play. J Spine Surg. 2017;3(3):433.

57. Mokawem M, Katzouraki G, Harman CL, Lee R. Lumbar interbody fusion rates with 3D-printed lamellar titanium cages using a silicate-substituted calcium phosphate bone graft. J Clin Neurosci. 2019;68:134-139.

58. Chung SS, Lee KJ, Kwon YB, Kang KC. Characteristics and efficacy of a new 3-dimensional printed mesh structure 
titanium alloy spacer for posterior lumbar interbody fusion. Orthopedics. 2017;40(5):e880-e885.

59. Bergmann C, Lindner M, Zhang W, et al. 3D printing of bone substitute implants using calcium phosphate and bioactive glasses. J Eur Ceramic Soc. 2010;30(12):2563-2567.

60. Cox SC, Thornby JA, Gibbons GJ, Williams MA, Mallick KK. 3D printing of porous hydroxyapatite scaffolds intended for use in bone tissue engineering applications. Mater Sci Eng C Mater Biol Appl. 2015;47:237-247.

61. Inzana JA, Olvera D, Fuller SM, et al. 3D printing of composite calcium phosphate and collagen scaffolds for bone regeneration. Biomaterials. 2014;35(13):4026-4034.

62. Bracaglia LG, Smith BT, Watson E, Arumugasaamy N, Mikos AG, Fisher JP. 3D printing for the design and fabrication of polymer-based gradient scaffolds. Acta Biomater. 2017;56:3-13.

63. Babilotte J, Guduric V, Le Nihouannen D, Naveau A, Fricain JC, Catros S. 3D printed polymer-mineral composite biomaterials for bone tissue engineering: fabrication and characterization. $J$ Biomed Mater Res B Appl Biomater. 2019;107(8):2579-2595.

64. Alehosseini M, Golafshan N, Kharaziha M, Fathi M, Edris H. Hemocompatible and bioactive heparin-loaded PCL$\alpha$-TCP fibrous membranes for bone tissue engineering. Macromol Biosci. 2018;18(6):1800020.

65. Ma L, Wang X, Zhao N, et al. Integrating 3D printing and biomimetic mineralization for personalized enhanced osteogenesis, angiogenesis, and osteointegration. ACS Appl Mater Interfaces. 2018;10(49):42146-42154.

66. Hallman M, Driscoll JA, Lubbe R, et al. Influence of geometry and architecture on the in vivo success of 3D-printed scaffolds for spinal fusion. Tissue Eng Part A. 2021;27(1-2):2636.

67. Jakus AE, Rutz AL, Jordan SW, et al. Hyperelastic "bone": a highly versatile, growth factor-free, osteoregenerative, scalable, and surgically friendly biomaterial. Sci Transl Med. 2016;8(358):358ra127-358ra127.

68. Driscoll JA, Lubbe R, Jakus AE, et al. 3D-printed ceramic-demineralized bone matrix hyperelastic bone composite scaffolds for spinal fusion. Tissue Eng Part A. 2020;26(34):157-166.
69. Dewey MJ, Nosatov AV, Subedi K, Shah R, Jakus A, Harley BA. Inclusion of a 3D-printed Hyperelastic bone mesh improves mechanical and osteogenic performance of a mineralized collagen scaffold. Acta Biomater. 2021;121:224-236.

70. Plantz MA, Lyons JG, Paul J, et al. 241. Preclinical safety and performance assessment of a novel 3D-printed HADBM composite scaffold using a rodent posterolateral fusion model. Spine J. 2020;20(9):S119.

Disclosures and COI: Mark A. Plantz has no conflicts of interest to declare. Erik B. Gerlach has no conflicts of interest to declare. Wellington K. Hsu has the following conflicts of interest to declare: Royalties: Stryker; Consulting: Stryker, AlloSource, Wright Medical, Medtronic, Mirus; Speaking and/ or Teaching Arrangements: AONA; Trips/Travel: Stryker, Medtronic, Micro Medicine; Board of Directors: Lumbar Spine Research Society, American Academy of Orthopaedic Surgeons, North American Spine Society, Cervical Spine Research Society; Scientific Advisory Board: Bioventus; Grants: Medtronic.

Corresponding Author: Mark A. Plantz, BS, Northwestern University-Feinberg School of Medicine, 420 E. Superior St, Chicago, IL 60611. Phone: (630) 776-5775; Email: m-plantz@northwestern. edu.

Published 30 April 2021

This manuscript is generously published free of charge by ISASS, the International Society for the Advancement of Spine Surgery. Copyright (C) 2021 ISASS. To see more or order reprints or permissions, see http://ijssurgery.com. 